\title{
Clinical effects of two different doses of duloxetine compared to conventional analgesic therapy in patients with osteoarthritis knee
}

\author{
Arpita Choudhury ${ }^{1}$, Dipasri Bhattacharya ${ }^{2}$, Rajasree Biswas ${ }^{3}$, Swati Saroha ${ }^{4}$, \\ Nitisha Chakraborty ${ }^{5}$, Samrat Roy ${ }^{6}$
}

\begin{abstract}
${ }^{1}$ Assistant Professor, ${ }^{2}$ Professor and Head, ${ }^{3}$ Associate Professor, 5,6 Senior Resident, Department of Anaesthesiology, Critical Care Medicine and Pain management, R G Kar Medical College and Hospital, Kolkata, West Bengal, India, ${ }^{4} J u n i o r$ Consultant, Department of Anaesthesiology, AMRI, Saltlake, West Bengal, India
\end{abstract}

\section{A B S T R A C T}

Background: Pain is the leading symptom of knee osteoarthritis (OA) leading to significant morbidity and decreased quality of life. Duloxetine, a selective serotonin norepinephrine reuptake inhibitor, has been demonstrated to have a centrally acting analgesic effect. Aims and Objectives: To evaluate the efficacy and safety of two different doses of duloxetine and compare with conventional pharmacotherapy in treatment of chronic pain due to osteoarthritis of knee. Materials and Methods: Ninety patients with symptomatic knee OA were randomly divided into 3 groups to receive duloxetine $40 \mathrm{mg} \mathrm{\&} 3 \mathrm{~g}$ paracetamol/ day (Group A), duloxetine $20 \mathrm{mg} \mathrm{\&} 3 \mathrm{~g}$ paracetamol/day (Group B) and paracetamol 3gm/ day (Group C). Patients were followed up for 6 months to assess pain relief and functional improvement. Visual Analogue Scale (VAS) for assessing pain intensity and Western Ontario and McMaster Universities Arthritis Index (WOMAC) questionnaire physical function subscale for assessing physical function were used. Results: Reduction in VAS score from baseline was significantly high in groups $A$ and $B$ as compared to $C$ at 1 month, 3 months and 6 months. Reduction in WOMAC score from baseline were also significantly high in groups $A$ and $B$ as compared to $C$ at 1 month, 3 month and 6 months. Adverse effects in Group A were significantly high as compared to group B and C. Patients discontinuing due to adverse effects were significantly high in group A. Conclusion: Lower dose of duloxetine is associated with significant pain reduction and improved function with lesser adverse effects

Access this article online Website:

http://nepjol.info/index.php/AJMS DOI: 10.3126/ajms.v12i10.37479

E-ISSN: 2091-0576

P-ISSN: 2467-9100

Copyright (c) 2021 Asian Journal of Medical Sciences

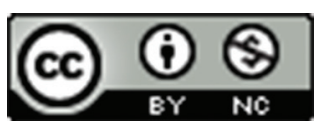

This work is licensed under a Creative Commons Attribution-NonCommercial 4.0 International License. in patients with pain due to knee OA.

Keywords: Osteoarthritis of knee; Pain; Duloxetine; Lower doses; Efficacy; Adverse effects

\section{INTRODUCTION}

Osteoarthritis (OA) of the knee is a common degenerative condition of the knee which is characterized by pain and limitation of joint movements. It significantly affects the quality of life. The overall prevalence of OA of the knee in India is $28.7 \%$. It is more common in females, particularly after 45 years of age with a prevalence of $31.6 \%$
The main symptoms of OA of knee are pain with limitation of movements. The goals of management of OA of knee are reduction of pain and restoring the function. In early stages, pain can be managed by analgesics, exercises and other physical therapy. Role of Hyaluronic acid, Steroid and Platelet Rich Plasma is still not well established particularly in advanced stage.

Thus, advanced OA of knee is difficult to treat and total knee replacement (TKR) surgery is established as standard 
care when conservative management fails to give enough pain relief and to restore function. ${ }^{2-6}$

But TKR surgery also has number of disadvantages apart from costs. Pain may worsen or persists in a significant number of patients after TKR. The prevalence of post TKR pain is around $20 \% \cdot{ }^{6-10} \mathrm{OA}$ of knee is a disease of elderly and comorbidities in elderly is an important factor where TKR surgery may not be possible.

Thus, there is a need for an efficient, safe and long-term pain-relieving method/procedure for patients who are not willing for TKR or who are not fit for TKR.

Duloxetine is a serotonin norepinephrine reuptake inhibitor (SNRI) and it is hypothesized that potentiation of 5-HT and NE activity in the CNS results in pain inhibition. ${ }^{12}$ The analgesic properties of duloxetine have been demonstrated in several chronic pain conditions such as pain associated with diabetic peripheral neuropathy, ${ }^{12,13}$ fibromyalgia ${ }^{14,15}$ and chronic low back pain. ${ }^{16,17}$ There is also preclinical ${ }^{18}$ and clinical evidence that duloxetine is beneficial for lowering chronic knee OA pain compared with a placebo. ${ }^{19-24}$

The recommended dose for knee OA pain is $60 \mathrm{mg}$ once daily. Some patients may require dosages above $60 \mathrm{mg}$ /day up to a maximum dose of $120 \mathrm{mg} /$ day. But higher doses have been associated with higher rate of adverse reactions. So, lower doses (i.e., $20 \mathrm{mg}, 40 \mathrm{mg}$ ) may be considered in treatment of $\mathrm{OA}$ of knee for tolerability reasons.

However, there are lack of literatures to compare the efficacy of lower doses of Duloxetine for chronic knee OA pain relief. So, we propose the present study to assess the pain relief and functional improvement after treatment with two lower doses of Duloxetine (i.e.,20 $\mathrm{mg}$ and $40 \mathrm{mg}$ ) and after conventional pharmacotherapy (with Paracetamol $3 \mathrm{~g} /$ day) in patients with osteoarthritis of knee.

\section{OBJECTIVES}

\section{Primary objective}

To assess pain relief and functional improvement after treatment with two different doses of Duloxetine in patients with osteoarthritis knee up to 6 months.

\section{Secondary objectives}

1. To assess the side effect profile of the treatment allocated to the three groups

2. To calculate the proportion of the patients leaving the study due to the side effects associated with the treatment.

\section{MATERIALS AND METHODS}

\section{Study population}

Patients diagnosed with osteoarthritis of knee attending the Pain Clinic of a tertiary care centre in eastern India.

\section{Study design}

The study is a prospective interventional study.

\section{Study duration}

The time frame of the study was between $1^{\text {st }}$ August 2020 to $31^{\text {st }}$ January 2021.

\section{Sample size}

Thirty patients fulfilling the inclusion criteria were allocated to each of the 3 groups. The study included both the gender diagnosed with osteoarthritis of knee attending Pain Clinic of R G Kar Medical College, Kolkata for knee pain.

\section{Inclusion criteria}

- Age between 40 years and 75 years

- Osteoarthritis knee grade II, III and grade IV (according to Kellgren-Lawrence Classification System $)^{26}$

- Pain more than 3 months (Assessed by VAS score)

- Patients not willing to undergo or contraindicated for knee replacement surgery.

\section{Exclusion criteria}

- Patient refusal

- History of previous knee surgery

- Knee pain due to other pathology such as lumbar radiculopathy, facet joint arthropathy, bony fracture etc.

- Inability to comprehend pain score

- Uncontrolled blood sugar

- Allergy to Duloxetine/acetaminophen/NSAIDs

- Pregnancy.

\section{Study procedure}

After taking approval from the institutional ethics committee, the patients diagnosed with osteoarthritis of knee with chronic pain were included in the study fulfilling inclusion criteria. The study was conducted in accordance with the Helsinki Declaration-2013 in the Text. After taking written informed consent from each patient, the patients were randomly allocated to one of the 3 study groups using computer generated sequence of random number. The study group named as 'Group A' for patients allocated to receive $40 \mathrm{mg}$ of oral duloxetine $\& 3 \mathrm{~g}$ of oral paracetamol/day, 'Group B' for patients allocated to receive $20 \mathrm{mg}$ of oral duloxetine \& $3 \mathrm{~g}$ of oral paracetamol/day and 'Group C' for patients allocated to receive conventional analgesic pharmacotherapy with oral paracetamol (3g/day). 
The patients were counselled to avoid all other products that contain paracetamol. Along with the pharmacotherapy allocated to the patients, all the patients participating in the study were advised to perform quadriceps strengthening exercises throughout the study period. The patients were followed up for 6 months to assess the pain relief and functional improvement.

Visual Analogue Scale (VAS) score for assessing pain intensity and Western Ontario and McMaster Universities Arthritis Index (WOMAC) questionnaire physical function subscale for assessing physical function of the joint were used prior to initiation of the treatment at the patients' first visit to the hospital as well as after 2 weeks, $1^{\text {st }}$ month, $3^{\text {rd }}$ month, $6^{\text {th }}$ month after starting treatment during follow up visits. The VAS score and WOMAC questionnaire physical function subscale were explained to the patients on first visit.

The Visual Analogue Scale (VAS) consists of a $10 \mathrm{~cm}$ long straight line with the endpoints defining extreme limits such as ' 0 ' indicates 'no pain at all' and ' 10 ' indicates 'pain as bad as it could be'. ${ }^{26}$

The WOMAC questionnaire physical function subscale is a self-administered questionnaire consisting of 17 items: using stairs, rising from sitting, standing, bending, walking, getting in/out of a car, shopping, putting on/taking off socks, rising from bed, lying in bed, getting in/out of bath, sitting, getting on/off toilet, heavy domestic duties, light domestic duties. The test questions are scored on a scale of $0-4$, which correspond to: None (0), Mild (1), Moderate (2), Severe (3), and Extreme (4). ${ }^{27}$

\section{Statistical analysis}

Data were collected on a Microsoft Excel ${ }^{\circledR}$ sheet and expressed as ratio and proportion. The age, sex, body weight of three groups were compared for similarity. The results were analyzed using repeated measures analysis of variance (ANOVA) using Statistical Package for the Social Sciences ${ }^{\circledR}$ version 23 (SPSS Inc., Chicago, IL, USA) for windows.

\section{Data collection}

VAS score and functional improvement were assessed using WOMAC questionnaire physical function subscale prior to initiation of the treatment at the patients' first visit to the hospital as well as after 2 weeks, $1^{\text {st }}$ month, $3^{\text {rd }}$ month, $6^{\text {th }}$ month after starting treatment during follow up visits.

\section{RESULTS}

\section{Study flow and patient characteristics}

Recruitment began on $1^{\text {st }}$ October 2019 and 90 patients were randomly allocated into the 3 groups. Most of the patients were women, with a comparable mean age and BMI (Table 1). The groups also had similar clinical characteristics at baseline (Table 2). The treatment adherence details of participants are shown in Figure 1.

\section{Clinical outcomes}

As illustrated in Table 3, Figure 2 and Figure 3, pain relief as compared by reduction in VAS score from baseline was significantly high in groups $\mathrm{A}$ and $\mathrm{B}$, as compared to $\mathrm{C}$ at 1 month, 3 month and 6 month (p 0.00). However, the pain relief at 2 weeks between group $B$ and $C$ were not significant, but that of between $A$ and $C$ were significant $(p$ 0.006 ). Functional improvement as assessed by reduction in WOMAC score from baseline were also significantly high in groups $\mathrm{A}$ and $\mathrm{B}$ as compared to $\mathrm{C}$ at 1 month, 3 month and 6 months (p 0.00).

\section{Safety and adverse effects}

Overall, the adverse effects in Group A were significantly high as compared to group $B$ and $C$. The adverse effects of group $B$ and $C$ were however comparable. In group $A$ side effect like fatigue $(65 \%)$, nausea $(52 \%)$ was high followed by constipation (48\%) and palpitation (43\%). There was no complaint of constipation and palpitation in group $\mathrm{C}$ (Table 4, Figure 4). A total of 13 patients discontinued treatment, 7 of whom were due the adverse effects of drugs and 6 left due to unsatisfactory pain relief. Patients discontinuing due to adverse effects were significantly high (0.002) in group A, with a total of 6 patients $(20 \%)$ leaving Group A and 1 patient (3.3\%) leaving Group B. However, discontinuation due unsatisfactory pain relief was maximum in group $C$ that was $4(13.3 \%)$ though (Table 5).

\section{DISCUSSION}

Pain in OA of knee remains an undertreated problem and the inability to adequately treat the pain of OA may lead to increased morbidity, but may also, as evidence shows, significantly increase mortality. ${ }^{22}$

Evidence from this study showed that patients with knee OA treated for 6 months with lower doses of duloxetine versus those treated with paracetamol had significantly greater pain reduction. This was observed by the significant improvement in pain assessment scores in

\begin{tabular}{lccc}
\multicolumn{4}{l}{ Table 1: Demographics } \\
Characteristics & Group A & Group B & Group C \\
\hline Age (Years) & $60.09(5.49)$ & $60.21(5.36)$ & $60.31(4.81)$ \\
Mean (SD) & & & \\
Female, N (\%) & $14(60.8)$ & $16(57.1)$ & $16(61.5)$ \\
BMl (Kg/m2) & $28.87(2.83)$ & $28.68(2.97)$ & $29.01(2.98)$ \\
Mean (SD) & & & \\
\hline
\end{tabular}




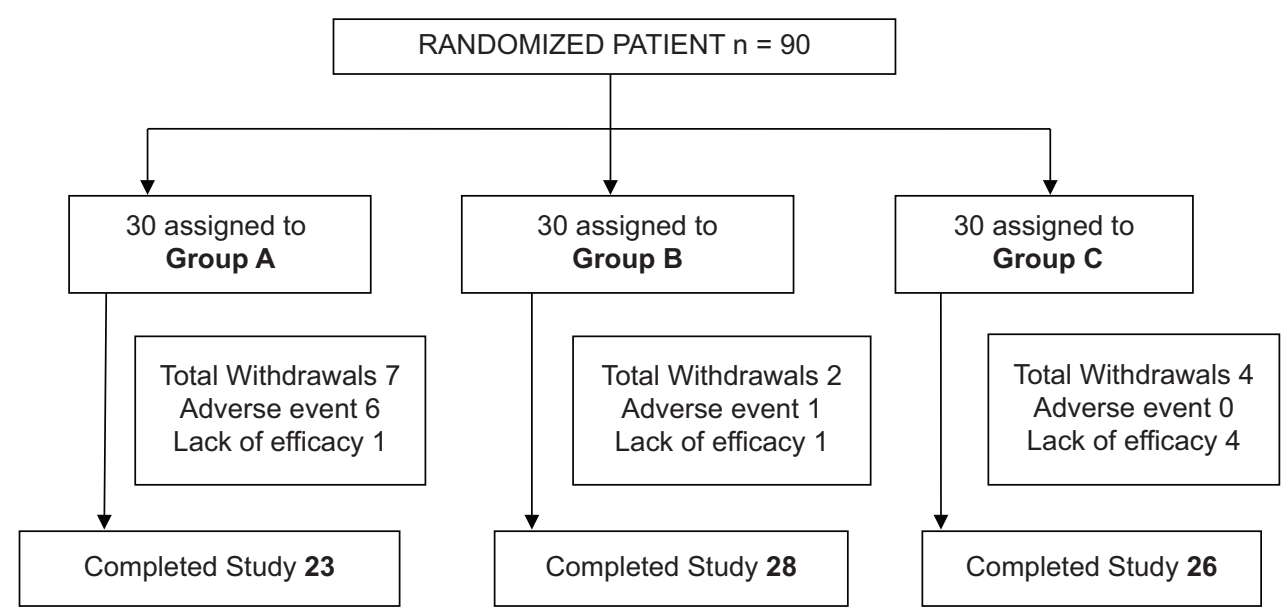

Figure 1: Trial profile (consort diagram). The treatment adherence details of participants are shown in Fig 1

\begin{tabular}{lcccc} 
Table 2: Patient Characteristics at Baseline & & & \\
Characteristics & Group A (N=23) & Group B (N=28) & Group C (N=26) & $\begin{array}{c}\text { Significance } \\
\text { P value }\end{array}$ \\
\hline Mean Baseline VAS (SD) & $6.70(0.63)$ & $6.64(0.62)$ & $6.65(0.62)$ & 0.953 \\
Mean Baseline WOMAC (SD) & $34.00(4.07)$ & $33.79(4.25)$ & $33.77(4.46)$ & 0.978 \\
\hline
\end{tabular}

\begin{tabular}{|c|c|c|c|c|c|c|c|c|c|}
\hline $\begin{array}{l}\text { Reduction in } \\
\text { scores from } \\
\text { baseline }\end{array}$ & Group A & $\begin{array}{c}\text { Group } \\
\text { B }\end{array}$ & $\begin{array}{c}\text { Group } \\
\text { C }\end{array}$ & $\begin{array}{c}\text { Group A vs } \\
\text { Group B } \\
\text { P value }\end{array}$ & $\begin{array}{l}\text { Lower } \\
\text { bound } \\
\text { Upper } \\
\text { bound } \\
(95 \% \mathrm{Cl})\end{array}$ & $\begin{array}{l}\text { Group B vs } \\
\text { Group C } \\
\text { P value }\end{array}$ & $\begin{array}{l}\text { Lower } \\
\text { bound } \\
\text { Upper } \\
\text { bound } \\
(95 \% \mathrm{Cl})\end{array}$ & $\begin{array}{c}\text { Group A vs } \\
\text { Group C } \\
\text { P value }\end{array}$ & $\begin{array}{l}\text { Lower } \\
\text { bound } \\
\text { Upper } \\
\text { bound } \\
(95 \% \mathrm{Cl})\end{array}$ \\
\hline VAS & 3.30 & 2.86 & 2.58 & 0.119 & -.09 & 0.402 & -.24 & 0.006 & .18 \\
\hline 2weeks & $(0.73)$ & $(0.84)$ & $(0.80)$ & & .98 & & .80 & & 1.27 \\
\hline VAS & 3.91 & 3.75 & 2.73 & 0.778 & -.41 & 0.000 & .46 & 0.000 & .60 \\
\hline 1 Month & $(0.84)$ & $(0.92)$ & $(0.78)$ & & .74 & & 1.58 & & 1.77 \\
\hline VAS & 4.43 & 4.00 & 3.00 & 0.128 & -.09 & 0.000 & .49 & 0.000 & .90 \\
\hline 3 Month & $(0.84)$ & $(0.81)$ & $(0.69)$ & & 0.96 & & 1.51 & & 1.97 \\
\hline VAS & 4.52 & 4.14 & 3.15 & 0.253 & -.19 & 0.000 & .44 & 0.000 & .79 \\
\hline 6 Month & $(0.84)$ & $(0.80)$ & $(0.88)$ & & .95 & & 1.54 & & 1.94 \\
\hline WOMAC 1 & 6.74 & 5.46 & 2.12 & 0.248 & -.62 & 0.000 & 1.52 & 0.000 & 2.70 \\
\hline Month & $(3.26)$ & $(3.53)$ & $(0.76)$ & & 3.17 & & 5.18 & & 6.55 \\
\hline WOMAC 3 & 10.00 & 8.50 & 3.50 & 0.197 & -.56 & 0.000 & 3.01 & 0.000 & 4.40 \\
\hline Month & (3.90) & $(3.91)$ & $(1.55)$ & & 3.56 & & 6.99 & & 8.60 \\
\hline WOMAC 6 & 10.70 & 9.00 & 3.65 & 0.102 & -.26 & 0.000 & 3.46 & 0.000 & 5.06 \\
\hline Month & (3.67) & (3.09) & $(1.64)$ & & 3.65 & & 7.24 & & 9.03 \\
\hline
\end{tabular}

\begin{tabular}{|c|c|c|c|c|c|c|c|c|c|}
\hline Adverse effects & $\begin{array}{c}\text { Group } \\
\text { A } \\
(\%)\end{array}$ & $\begin{array}{c}\text { Group } \\
\text { B } \\
(\%)\end{array}$ & $\begin{array}{c}\text { Group } \\
\text { C } \\
(\%)\end{array}$ & $\begin{array}{c}\text { Group A } \\
\text { Vs } \\
\text { Group B } \\
\text { P Value }\end{array}$ & $\begin{array}{l}\text { Lower } \\
\text { Bound } \\
\text { Upper } \\
\text { Bound } \\
\text { (95\%Ci) }\end{array}$ & $\begin{array}{c}\text { Group B Vs } \\
\text { Group C } \\
\text { P Value }\end{array}$ & $\begin{array}{l}\text { Lower } \\
\text { Bound } \\
\text { Upper } \\
\text { Bound } \\
\text { (95\%Ci) }\end{array}$ & $\begin{array}{c}\text { Group A Vs } \\
\text { Group C } \\
\text { P Value }\end{array}$ & $\begin{array}{l}\text { Lower } \\
\text { Bound } \\
\text { Upper } \\
\text { Bound } \\
(95 \% \mathrm{Ci})\end{array}$ \\
\hline Nausea & 52 & 21 & 4 & 0.019 & $\begin{array}{l}.04 \\
.57\end{array}$ & 0.234 & $\begin{array}{l}-.08 \\
.43\end{array}$ & 0.000 & $\begin{array}{l}.21 \\
.75\end{array}$ \\
\hline Fatigue & 65 & 18 & 12 & 0.000 & $\begin{array}{l}.20 \\
.74\end{array}$ & 0.833 & $\begin{array}{l}-.20 \\
.33\end{array}$ & 0.000 & $\begin{array}{l}.26 \\
.81\end{array}$ \\
\hline Constipation & 48 & 14 & 0 & 0.003 & $\begin{array}{l}.10 \\
.57\end{array}$ & 0.301 & $\begin{array}{l}-.09 \\
.37\end{array}$ & 0.000 & $\begin{array}{l}.24 \\
.72\end{array}$ \\
\hline Palpitation & 43 & 11 & 0 & 0.002 & $\begin{array}{l}.10 \\
.55\end{array}$ & 0.473 & $\begin{array}{r}-.11 \\
.33\end{array}$ & 0.000 & $\begin{array}{l}.21 \\
.66\end{array}$ \\
\hline
\end{tabular}




\begin{tabular}{lcccc} 
Table 5: Proportion of Patients lost during study & & \\
& Group A (N=30) & Group B (N=30) & Group C (N=30) & P Value \\
\hline Total discontinued & $7(23.33 \%)$ & $2(6.67 \%)$ & $4(13.33 \%)$ & 0 \\
Discontinued due to adverse effect & $6(20 \%)$ & $1(3.33 \%)$ & $4(13.33 \%)$ & 0.002 \\
Discontinued due to non-satisfaction & $1(3.33 \%)$ & $1(3.33 \%)$ & $26(86.67 \%)$ & 0.212 \\
Total completed & $23(76.67 \%)$ & $28(93.33 \%)$ & \\
\hline
\end{tabular}

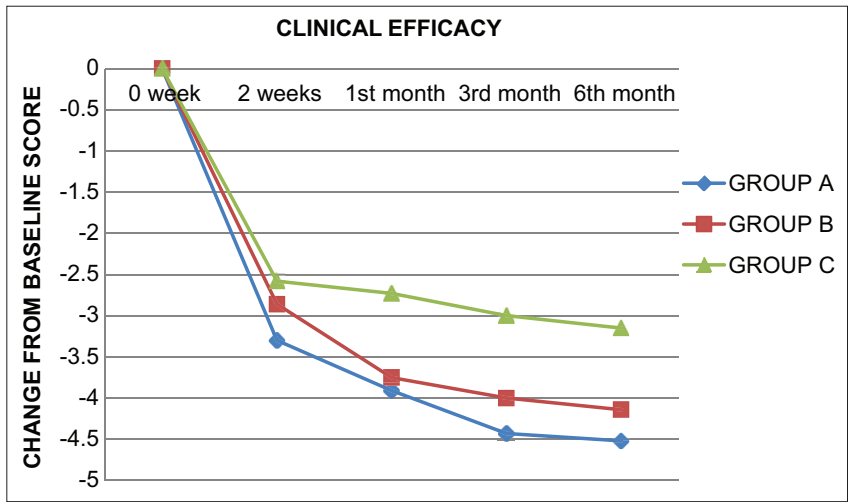

Figure 2: Reduction in VAS score from baseline Pain relief as compared by reduction in VAS score from baseline was significantly high in groups $A$ and $B$, as compared to $C$ at 1 month, 3 month and 6 months. However, the pain re-lief at 2 weeks between group $B$ and $C$ were not significant, but that of between $A$ and $C$ were significant

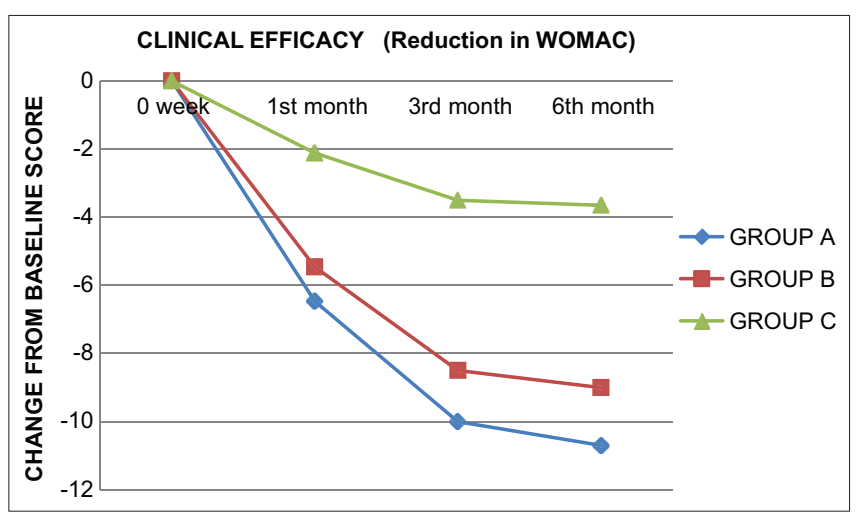

Figure 3: Reduction in WOMAC score from baseline Functional improvement as assessed by reduction in WOMAC score from baseline were sig-nificantly high in groups $A$ and $B$ as compared to $C$ at 1 month, 3 month and 6 months

the duloxetine groups (Gr. A, Gr. B) compared with the paracetamol group (Gr. C). Pain relief as compared by reduction in VAS score from baseline was significantly high in groups $\mathrm{A}$ and $\mathrm{B}$ as compared to $\mathrm{C}$ at 1 month, 3 month and 6 month (p 0.00). However, the pain relief at 2 weeks between group $B$ and $C$ were not significant, but that of between $A$ and $C$ were significant ( $p$ 0.006). Functional improvement as assessed by reduction in WOMAC score from baseline were also significantly high in groups $\mathrm{A}$ and $\mathrm{B}$ as compared to $\mathrm{C}$ at 1 month, 3 months and 6 months $(\mathrm{p}<0.001)$.

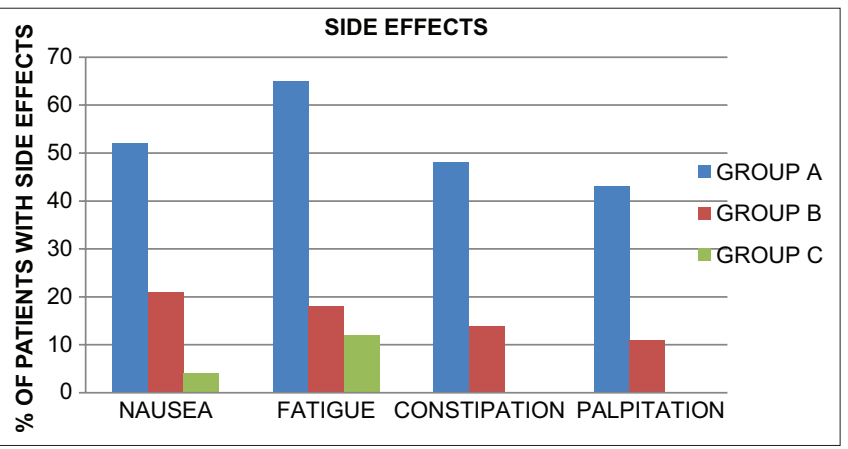

Figure 4: Percentage of patients with side effects Overall, the adverse effects in Group A were significantly high as compared to group B and C. The adverse effects of group $B$ and $C$ were however comparable. In group A side effect like fatigue (65\%), nausea $(52 \%)$ was high followed by constipation (48\%) and palpitation (43\%). There was no complaint of constipation and palpitation in group $\mathrm{C}$

The overall adverse effects in Group A were significantly high as compared to group B and C. However, the adverse effects of group $\mathrm{B}$ and $\mathrm{C}$ were comparable. In group A side effects like fatigue, nausea was high followed by constipation and palpitation. Patients discontinuing due to adverse effects were significantly high in group $\mathrm{A}$.

These observations are consistent with the previously reported association of duloxetine with pain reduction in chronic pain due to chronic back pain and fibromyalgia. ${ }^{24,29}$ The alleviation of pain in the duloxetine group is consistent with the role of 5-hydroxytryptamine (5-HT) and NE as modulators of descending pain pathways in the brain and spinal cord. ${ }^{30,31}$

Chappell A et al., ${ }^{21}$ evaluated the efficacy and safety of duloxetine in the treatment of chronic pain due to osteoarthritis of knee. Patients were randomized to either duloxetine $60 \mathrm{mg}$ once daily or placebo. At week 7 , the duloxetine dosage was increased, in a blinded fashion, to $120-\mathrm{mg}$ OD in patients reporting $<30 \%$ pain reduction. Treatment with duloxetine 60 $\mathrm{mg}$ to $120 \mathrm{mg}$ OD was associated with significant pain reduction and improved function. But, significantly more duloxetine-treated patients discontinued the trial because of adverse events.

Hochberg et al., ${ }^{32}$ performed a pooled analysis of OA-1 [Chappell et al., 2009c] ${ }^{20}$ and OA-2 [Chappell et al., 2011] ${ }^{21}$ 
and revealed that duloxetine patients were 33\% more likely to have a clinically meaningful response to treatment than placebo patients. Also, more duloxetine than placebo patients reported $>30 \%$ improvement in pain from baseline to end point and improvements $>50 \%$ occurred more often in the duloxetine group. The authors concluded that duloxetine is clinically effective on both pain and function. But duloxetine patients experienced more treatment-related adverse event than placebo patients.

Frakes E et al., studied the efficacy, tolerability, and safety of duloxetine when added to oral nonsteroidal anti-inflammatory drugs (NSAIDs) in patients with osteoarthritis of knee with pain of moderate or greater severity. ${ }^{33}$ In this study, 524 patients randomly received duloxetine $60 / 120 \mathrm{mg} /$ day $(\mathrm{N}=264)$ or placebo $(\mathrm{N}=260)$. They found that duloxetine added to oral NSAID therapy provided additional significant pain reduction, improved function, and patient-rated impression of improvement. But, discontinuation due to adverse events also occurred more commonly in the duloxetine group than the placebo group. These findings are similar to our study, though the dose of oral duloxetine used in our study were lesser than the above-mentioned studies leading to less of adverse effects.

Abou-Raya et al., also found similar results in an independent 16-week trial evaluating duloxetine 60 $\mathrm{mg} /$ day and placebo in OAKP in older patients; $\geq 65$ years. ${ }^{34}$ The authors found that the duloxetine group had a significantly greater reduction in pain and physical function (WOMAC function scores) relative to placebo. They also reported that the duloxetine group had a significantly greater reduction in paracetamol use at 16 weeks. But duloxetine patients had significantly more constipation, nausea, hyperhidrosis, cough, myalgia, arthralgia and palpitation.

These above observations are also consistent with our study in terms of efficacy, but the side effects reported were much less in the group receiving $20 \mathrm{mg}$ of oral duloxetine compared to the above-mentioned studies leading to better tolerability. This is probably due to using lower dose of duloxetine (i.e., $20 \mathrm{mg}$ ) in our study, that lead to lesser number of adverse effects compared to the recommended dose (60-120 mg).

The findings of the present study indicate that the use of lower doses (20-40 mg) of oral duloxetine have significant beneficial effect of improving pain symptoms which improves function and quality of life in patients with knee $\mathrm{OA}$, similar to the recommended relatively higher doses (60-120 mg) of duloxetine.
Optimum dose of oral duloxetine, used in our institution (a tertiary care centre in eastern India) is $20 \mathrm{mg}$ to treat $\mathrm{OA}$ of knee with significant pain reduction and improved function with lesser adverse effects leading to better tolerability of the treatment in older adults with knee OA.

\section{Limitations of the study}

The patient population utilised in this study included far more women than men, the patients were relatively young (around 60 years of age) and with a BMI of $28-29 \mathrm{Kg} /$ $\mathrm{m}^{2}$, raising the concern about selection bias. This was also an acute treatment trial, based on a 6 months trial and consequently the results may not generalise to a longer duration of treatment. Furthermore. the study included a small sample size. Hence longer-term trials involving larger sample size are required to fully assess the safety and efficacy of duloxetine in a time course that is more reflective of clinical practice.

\section{ACKNOWLEDGEMENT}

The authors wish to thank all the participating investigators and patients for their contributions to this study.

\section{REFERENCES}

1. Pal CP, Singh P, Chaturvedi S, Pruthi KK and Vij A. Epidemiology of knee osteoarthritis in India and related factors. Indian J Orthop. 2016;50(5):518-522.

https://doi.org/10.4103/0019-5413.189608

2. Lawson EH, Gibbons MM, Ingraham AM, Shekelle PG and Ko CY. Appropriateness criteria to assess variations in surgical procedure use in the United States. Arch Surg. 2011; 146:1433-1440.

https://doi.org/10.1001/archsurg.2011.581

3. Zhang W, Moskowitz RW, Nuki G, Abramson S, Altman RD, Arden $\mathrm{S}$, et al. OARSI recommendations for the management of hip and knee osteoarthritis, Part II: OARSI evidence-based, expert consensus guidelines. Osteoarthr Cartilage. 2008; 16:137-162.

https://doi.org/10.1016/j.joca.2007.12.013

4. Riddle DL, Jiranek WA and Hayes CW. Use of a validated algorithm to judge the appropriateness of total knee arthroplasty in the United States: a multicenter longitudinal cohort study. Arthritis Rheumatol. 2014; 66:2134-2143.

https://doi.org/10.1002/art.38685

5. Escobar A, Quintana JM, Arostegui I, Azkarata J, Guenaga JI, Arenaza JC, et al. Development of explicit criteria for total knee replacement. Int J Technol Assess Health Care. 2003; 19:57-70. https://doi.org/10.1017/S0266462303000060

6. Beswick AD, Wylde V, Gooberman-Hill R, Blom A, Dieppe P, et al. What proportion of patients report longterm pain after total hip or knee replacement for osteoarthritis? A systematic review of prospective studies in unselected patients. BMJ Open. 2012;2: e000435.

https://doi.org/10.1136/bmjopen-2011-000435 
7. Lenguerrand E, Wylde V, Gooberman-Hill R, Sayers A, BruntonL, Beswick $A D$, et al. Trajectories of Pain and Function after Primary Hip and Knee Arthroplasty: The ADAPT Cohort Study. PLoS One. 2016;11: e0149306.

https://doi.org/10.1371/journal.pone.0149306

8. Halket A, Stratford PW, Kennedy DM and Woodhouse LJ. Using hierarchical linear modeling to explore predictors of pain after total hip and knee arthroplasty as a consequence of osteoarthritis. J Arthroplasty. 2010; 25:254-262.

https://doi.org/10.1016/j.arth.2009.01.007

9. Phillips JR, Hopwood B, Arthur C, Stroud R and Toms AD. The natural history of pain and neuropathic pain after knee replacement: a prospective cohort study of the point prevalence of pain and neuropathic pain to a minimum three-year follow-up. Bone Joint J. 2014;96-B:1227-1233.

https://doi.org/10.1302/0301-620X.96B9.33756

10. Scott CE, Howie CR, MacDonald D and Biant LC. Predicting dissatisfaction following total knee replacement: a prospective study of 1217 patients. J Bone Joint Surg Br. 2010;92B:1253-1258.

https://doi.org/10.1302/0301-620X.92B9.24394

11. Benn $S$ and Woolf $C$. Adult neuron survival strategies-slamming on the brakes. Nat Rev Neurosci. 2004; 5: 686-700. https://doi.org/10.1038/nrn1477

12. Goldstein D, Lu Y, Detke M, Lee T and lyengar S. Duloxetine vs. placebo in patients with painful diabetic neuropathy. Pain. 2005; 116: 109-118.

https://doi.org/10.1016/j.pain.2005.03.029

13. Raskin J, Pritchett $Y$, Wang F, D'Souza D, Waninger A, lyengar S. et al. A double-blind, randomized multicenter trial comparing duloxetine with placebo in the management of diabetic peripheral neuropathic pain. Pain Med. 2005; 6: 346-356.

https://doi.org/10.1111/j.1526-4637.2005.00061.x

14. Arnold L, Rosen A, Pritchett Y, D'Souza D, Goldstein D, lyengar S, et al. HMCA - A randomized, double-blind, placebocontrolled trial of duloxetine in the treatment of women with fibromyalgia with or without major depressive disorder. Pain. 2005; 119: 5-15.

https://doi.org/10.1016/j.pain.2005.06.031

15. Russell I, Mease P, Smith T, Kajdasz D, Wohlreich M, Detke M, et al. HMCJ - Efficacy and safety of duloxetine for treatment of fibromyalgia in patients with or without major depressive disorder: Results from a 6-month, randomized, double-blind, placebo-controlled, fixed-dose trial. Pain.2008; 136: 432-444. https://doi.org/10.1016/j.pain.2008.02.024

16. Skljarevski V, Ossanna M, Liu-Seifert H, Zhang Q, Chappell A, lyengar S, et al. A double-blind, randomized trial of duloxetine versus placebo in the management of chronic low back pain. Eur J Neurol. 2009; 16: 1041-1048.

https://doi.org/10.1111/j.1468-1331.2009.02648.x

17. Skljarevski V, Zhang S, Desaiah D, Alaka K, Palacios S, Miazgowski T, et al. Duloxetine versus placebo in patients with chronic low back pain: a 12-week, fixed-dose, randomized, double-blind trial. J Pain. 2010b; 11: 1282-1290.

https://doi.org/10.1016/j.jpain.2010.03.002

18. Chandran P, Pai M, Blomme EA, Hsieh GC, Decker MW, Honore $\mathrm{P}$, et al. Pharmacological modulation of movementevoked pain in a rat model of osteoarthritis. Eur J Pharmacol. 2009; 613:39-45.

https://doi.org/10.1016/j.ejphar.2009.04.009

19. Sullivan MD, Bentley S, Fan MY and Gardner G. A singleblind, placebo run-in study of duloxetine for activity-limiting osteoarthritis pain. J Pain. 2009; 10:208-213. https://doi.org/10.1016/j.jpain.2008.08.009

20. Chappell AS, Ossanna MJ, Liu-Seifert $H$, lyenger $S$, Skljarevski V, Li LC, et al. Duloxetine, a centrally acting analgesic, in the treatment of patients with osteoarthritis knee pain: a 13-week, randomized, placebo-controlled trial. Pain. 2009; 146:253-260.

https://doi.org/10.1016/j.pain.2009.06.024

21. Chappell AS, Desaiah D, Liu Seifert H, Zhang S, Skljarevski V, Belenkov $Y$, et al. A double blind, randomized, placebo controlled study of the efficacy and safety of duloxetine for the treatment of chronic pain due to osteoarthritis of the knee. Pain Pract. 2011; 11:33-41.

https://doi.org/10.1111/j.1533-2500.2010.00401.x

22. Nuesch E, Dieppe P, Reichenbach S, Williams S, Iff S and Juni P. All cause and disease specific mortality in patients with knee or hip osteoarthritis: population based cohort study. BMJ. 2011; 342: d1165.

https://doi.org/10.1136/bmj.d1165

23. Trelle S, Reichenbach S, Wandel S, Hildebrand P, Tschannen B, Villiger PM, et al. Cardiovascular safety of non-steroidal antiinflammatory drugs: network meta-analysis. BMJ. 2011; 342: c7086. https://doi.org/10.1136/bmj.c7086

24. Altman R, Asch E, Bloch D, Bole G, Borenstein D, Brandt K, et al. Development of criteria for the classification and reporting of osteoarthritis. Classification of osteoarthritis of the knee. Diagnostic and Therapeutic Criteria Committee of the American Rheumatism Association. Arthritis Rheum. 1986; 29: 1039-1049. https://doi.org/10.1002/art.1780290816

25. Kohn MD, Sassoon AA and Fernando ND. Classifications in Brief: Kellgren-Lawrence Classification of Osteoarthritis. Clin Orthop Relat Res. 2016; 474(8):1886-1893. https://doi.org/10.1007/s11999-016-4732-4

26. Glossary, Spine: December 15, 2000 - Volume 25 - Issue 24 - p 3200-3202. https://doi.org/10.1097/00007632-200012150-00016

27. American College of Rheumatology. Western Ontario and McMaster Universities Osteoarthritis Index (WOMAC). http:// www.rheumatology.org/practice/clinical/clinicianresearchers/ outcomes-instrumentation/WOMAC.asp.

28. Bellamy N, Buchanan WW, Goldsmith $\mathrm{CH}$, Campbell $\mathrm{J}$ and Stitt LW. Validation study of WOMAC: a health status instrument for measuring clinically important patient relevant outcomes to antirheumatic drug therapy in patients with osteoarthritis of the hip or knee. J Rheumatol. 1988; 15(12):1833-1840.

29. Goldstein DJ, Lu Y, Detke MJ, Hudson J, lyengar S and Demitrack MA. Effects of duloxetine on painful physical symptoms associated with depression. Psychosomatics. 2004; 45(1): 17-28.

https://doi.org/10.1176/appi.psy.45.1.17

30. lyengar S, Webster AA, Henrick-Lucke SK, Xu JY and Simmons RMA. Efficacy of duloxetine, a potent and balanced serotonin-norepinephrine inhibitor in persistent pain models in rats. Journal of Pharmacology and Experimental Therapeutics. 2004; 311(2): 576-584.

https://doi.org/10.1124/jpet.104.070656

31. Wong DT and Bymaster FP. Dual serotonin and noradrenaline uptake inhibitor class of antidepressants-potential for greater efficacy or just hype? Prog Drug Res. 2002; 58: 169-222. https://doi.org/10.1007/978-3-0348-8183-8_5

32. Hochberg MC, Wohlreich M, Gaynor P, Hanna S and Risser R. Clinically relevant outcomes based on analysis of pooled data 
from 2 trials of duloxetine in patients with knee osteoarthritis. $\mathrm{J}$ Rheumatol. 2012; 39:352-358.

https://doi.org/10.3899/jrheum.110307

33. Frakes EP, Risser RC, Ball TD, Hochberg MC and Wohlreich MM. Duloxetine added to oral nonsteroidal anti-inflammatory drugs for treatment of knee pain due to osteoarthritis: results of a randomized, double-blind, placebo-controlled trial. Curr Med
Res Opin. 2011; 27(12):2361-2372.

https://doi.org/10.1185/03007995.2011.633502

34. Abou-Raya S, Abou-Raya A and Helmii M. Duloxetine for the management of pain in older adults with knee osteoarthritis: randomised placebo-controlled trial. Age Ageing. 2012; 41(5):646-652.

https://doi.org/10.1093/ageing/afs072

\section{Author's Contribution:}

AC- Concept and design of the study, prepared first draft of manuscript, Data collection, Statistical analysis, Interpretation of results and review of literature;

DB- Concept and design of the study, Interpretation of results, reviewed the literature and manuscript preparation, Supervision of the entire study; RB- Concept,

coordination, statistical analysis and interpretation, Preparation of manuscript and revision of the manuscript, Supervision of the entire study; SS- Data

collection, Statistical analysis, Interpretation of results, review of literature; NC- Coordination, statistical analysis and interpretation, Preparation of manuscript and revision of the manuscript; SR- Data collection, Statistical analysis, Interpreted the results.

\section{Work Attributed to}

R G Kar Medical College and Hospital, Kolkata, West Bengal, India.

\section{Orcid ID:}

Dr. Arpita Choudhury- (1) https://orcid.org/0000-0002-5929-9233

Prof. (Dr.) Dipasri Bhattacharya- (i) https://orcid.org/0000-0002-9001-1525

Dr. Rajasree Biswas- (10) https://orcid.org/0000-0001-5223-7913

Dr. Swati Saroha- (1) https://orcid.org/0000-0001-8218-9975

Dr. Nitisha Chakraborty- (i) https://orcid.org/0000-0001-9398-4464

Dr. Samrat Roy- (1) https://orcid.org/0000-0001-7802-4799 